\title{
KARAKTERISTIK PERIKANAN JARING CUMI DI UTARA JAWA
}

\author{
Hufiadi1) dan Mahiswara $^{1)}$ \\ 1) Peneliti pada Balai Riset Perikanan Laut, Muara Baru-Jakarta
}

Teregristrasi I tanggal: 4 Mei 2006; Diterima setelah perbaikan tanggal: 30 Mei 2007; Disetujui terbit tanggal: 8 Juni 2007

\begin{abstract}
ABSTRAK
Saat ini, perikanan jaring cumi khusus di Pulau Jawa berkembang pesat, keberadaannya dapat dijumpai terutama di Pelabuhan Perikanan Jakarta (Muara Baru dan Muara Angke), Indramayu, dan Juwana. Tulisan ini didasarkan pada hasil penelitian jaring nus (jaring cumi) di Juwana pada bulan Oktober 2004. Tujuan penelitian ini adalah untuk memberikan informasi dasar secara deskriptif mengenai karakteristik perikanan jaring cumi di perairan Laut Jawa meliputi intensitas cahaya lampu, alat tangkap, dan armada, aktivitas penangkapan, komposisi hasil tangkapan. Hasil penelitian menunjukkan bahwa kapal jaring cumi yang berbasis di Juwana diperoleh kisaran panjang 14,30 sampai dengan 19,10 m; lebar 4,35 sampai dengan 6,60 m; dalam 2,0 sampai dengan 2,5 m. Nelayan jaring cumi Juwana beroperasi di perairan utara Jawa pada posisi $03-04^{\circ} \mathrm{LS}$ dan $110-114^{\circ} \mathrm{BT}$. Dari hasil tangkapan jaring cumi didominasi oleh ikan siro (Ambygaster sirm) mencapai (83,58\%). Dari ke-3 titik pengukuran intensitas cahaya (pusat, tengah, dan haluan kapal), diperoleh variasi nilai pemudaran cahaya 0,1028 sampai dengan $0,2566 \mu \mathrm{mol} \mathrm{s}^{-1} \mathrm{~m}^{-2}$ per $\mathrm{m}$.
\end{abstract}

KATAKUNCl: jaring cumi, intensitas cahaya, hasil tangkapan

\section{ABSTRACT: Characteristic stick held dipnet fisheries in North Java. By: Hufiadi and Mahiswara}

Based on the of used lighting of lamp, stick held dipnet is belong to the light fishing classification. The stick held dipnet fisheries especially in Java grow rapidly, its existence can be met in Jakarta fishery port (Nizam Zahman and Muara Angke), Indramayu, and Juwana. This paper is based on the results of studies and observer on stick held dipnet boat in Juwana at October 2004. The stick held dipnet research was conducted to know of fishing gear, light illumination intensity, fishing activities, catch composition, and body length of dominated catch. The stick held dipnet boats based in Juwana has dimention with range i.e. Length (L) 14,30 to 19,10 m; Broad (B) 4,35 to 6,60 m; Depth (D) 2,0 to 2,5 m. The stick held dipnet Java waters fishing ground was $S 03-04^{\circ}$ and $E 110-114^{\circ}$ positions. From the catch of stick held dipnet are dominated by Ambygaster Sirm (83,58\%). From third point of measurement of light intensity (center, middle, and ship lower) on boat, it was found the variation of dull light illumination ranging from 0,1028 to 0,2566 $\mu$ mole of $s^{-}$ ${ }^{1} \mathrm{~m}^{-2}$ per $\mathrm{m}$.

\section{KEYWORDS: $\quad$ stick held dipnet, light fishing, catch}

\section{PENDAHULUAN}

Unit-unit perikanan tangkap yang menggunakan alat bantu cahaya di dalam pengoperasian diistilahkan sebagai light fishing. Alat tangkap yang menggunakan cahaya untuk menarik perhatian ikan dalam proses pengoperasian, merupakan salah satu teknologi penangkapan yang dianggap sukses dan mengalami perkembangan yang pesat (Arimoto, 1999). Prinsip penangkapan ikan yang menggunakan lampu tersebut pada dasarnya memanfaatkan faktor tingkah laku ikan. Menurut Ayodhyoa (1981), peristiwa berkumpul ikan di bawah sumber cahaya disebabkan adanya ikan yang secara langsung mendekati cahaya karena mempunyai sifat fototaksis positif atau ikan yang tidak secara langsung tertarik cahaya, melainkan karena ada makanan yang dapat dimangsa.
Akhir-akhir ini perikanan jaring cumi khususnya di Pulau Jawa berkembang pesat, keberadaannya dapat dijumpai terutama di Pelabuhan Perikanan Jakarta (Muara Baru dan Muara Angke), Indramayu, dan Juwana. Di Juwana jaring cumi ini dikenal dengan nama jaring nus. Alat tangkap jaring cumi merupakan hasil adopsi alat tangkap dari negara Thailand yang merupakan hasil modifikasi dari stick held dipnet yang ada di Thailand (Wahyono, 2004). Saat ini, relatif banyak kapal jaring cumi asal Thailand yang legal beroperasi di perairan Indonesia. Jaring cumi ini cukup efektif terutama untuk menangkap cumi-cumi dan ikan pelagis kecil lain.

Guna memperoleh informasi dan dapat mendeskripsikan beberapa aspek yang berkaitan dengan perikanan jaring cumi di wilayah pesisir utara Pulau Jawa dilakukan penelitian terhadap alat tangkap jaring cumi

Kosrespondensi penulis: 
yang berbasis di Juwana. Tulisan ini bertujuan untuk memberikan informasi dasar secara deskriptif mengenai karakteristik perikanan jaring cumi di perairan Laut Jawa meliputi intensitas cahaya lampu, alat tangkap, dan armada penangkapan, aktivitas penangkapan, musim dan daerah penangkapan, komposisi, dan ukuran hasil tangkapan yang dominan.

\section{BAHAN DAN METODE}

Tulisan ini merupakan hasil penelitian jaring cumi yang telah dilakukan pada bulan Oktober 2004, di Juwana, Jawa Tengah dengan cara mengikuti langsung kegiatan operasi penangkapan jaring cumi. Juga berdasarkan pada hasil observasi melalui mewawancarai nelayan jaring cumi di Pusat Pendaratan Ikan DKI Jakarta yaitu di Pelabuhan Muara Angke dan Muara Baru pada bulan September 2005.
Data yang diperoleh merupakan data primer dan data sekunder. Data primer berupa ukuran sebaran intensitas cahaya lampu kapal jaring cumi di dalam air secara vertikal, dimensi bahan dan alat tangkap, cara penangkapan, daerah penangkapan dan komposisi hasil tangkapan. Data sekunder berupa data armada data produksi jaring cumi.

lluminasi cahaya lampu dalam kolom air diukur dengan menggunakan quantum meter LI-192 SA dengan satuan $\mu \mathrm{mol} \mathrm{s} \mathrm{s}^{-1} \mathrm{~m}^{-2}$. Pengukuran sebaran vertikal cahaya dilakukan sampai dengan kedalaman di mana intensitas cahaya pada kolom air mencapai titik nol. Posisi pengukuran di atas perahu dilakukan pada 3 tempat sisi kapal lahan yang dianggap ada perbedaan dari sebaran kuat cahaya yang digunakan pada kapal jaring cumi yaitu (A) pusat cahaya lampu; (B) tengah; dan (C) haluan kapal (Gambar 1).

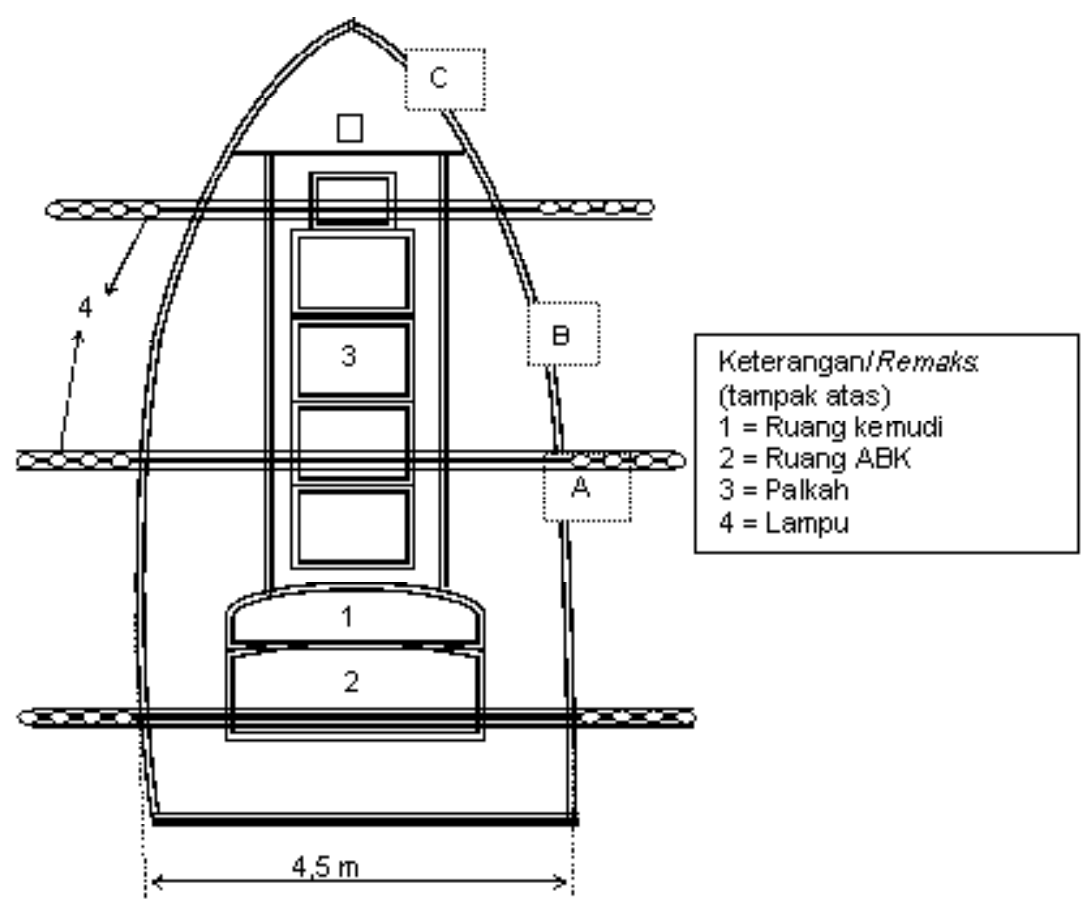

Gambar 1. Posisi pengukuran intensitas cahaya pada kapal jaring cumi. Keterangan: A) pusat cahaya; B) tengah; C) haluan kapal

Figure 1. Measurement position of light intencity on stick held dipnet boat i.e. Remarks: A) Center; B) middle; C) ship lower

Analisis terhadap intensitas cahaya dilakukan berupa analisis regresi intensitas cahaya di bawah kolom air dengan model persamaan (Nikoronov, 1975):

$$
\mathrm{Y}=a e^{\mathrm{kx}}
$$

di mana:

$\mathrm{Y}=$ intensitas cahaya pada kedalaman $\mathrm{x} \mathrm{m}$

$\mathrm{a}=$ konstanta

$$
\begin{aligned}
& \mathrm{k}=\text { koefisien pemudaran } \mu \mathrm{mol} \mathrm{s} \mathrm{s}^{-1} \mathrm{~m}^{-2} \text { per } \mathrm{m} \\
& \mathrm{x}=\text { kedalaman pengukuran }
\end{aligned}
$$

Untuk ikan yang dominan tertangkap oleh jaring cumi ditimbang dengan timbangan berkapasitas $2 \mathrm{~kg}$ dengan ketelitian $1 \mathrm{~g}$ dan diukur panjang cagak (fork length) dengan menggunakan measuring paperketelitian $0,5 \mathrm{~cm}$. Identifikasi hasil tangkapan mengacu pada referensi Tarp \& Kailola (1982). 


\section{HASIL DAN BAHASAN}

\section{Intensitas Cahaya Lampu}

Penggunaan cahaya sebagai alat bantu penangkapan ikan di Indonesia telah mengalami perkembangan yang pesat, sehingga dapat dipastikan bahwa, pada setiap sentra perikanan tangkap terdapat lampu yang digunakan untuk usaha penangkapan ikan. Tahun 1950-an jumlah lampu yang digunakan sebelum operasi penangkapan sangat terbatas dan hanya terdapat di daerah tertentu (Subani, 1983).

Posisi pengukuran cahaya unit jaring cumi secara vertikal dilakukan (pusat cahaya, tengah, dan ujung kapal) dengan daya lampu fluorocent (mercury, galaxy) 10.000 watt. Lampu dipasang menyebar pada ke-2 sisi kapal (kanan dan kiri ). Dari hasil pengukuran intensitas cahaya menunjukkan bahwa secara umum, pola sebaran cahaya lampu fluorocent tipe mercury dengan daya 10.000 watt, pada 3 titik (pusat cahaya, tengah, dan haluan kapal) cenderung memiliki pola sama. Pada Gambar 2, terlihat bahwa masing-masing sebaran intensitas cahaya dari permukaan $0 \mathrm{~m}$ sampai dengan kedalaman $1 \mathrm{~m}$ khusus di bagian atas kolom air menurun secara drastis. Selanjutnya, nilai sebaran cahaya berkurang seiring dengan bertambah kedalaman pengukuran dan pada kedalaman tertentu nilai intensitas cenderung tidak jauh berbeda antar posisi pengukuran. Hal ini, terlihat sebagai hubungan eksponensial antara nilai iluminasi cahaya dengan kedalaman pengukuran. Setelah itu, pada kedalaman sekitar $6 \mathrm{~m}$ di bawah permukaan laut nilai intensitas cahaya tampak sangat lemah. Fenomena seperti ini diduga sebagai akibat interferensi cahaya telah berkurang pada kedalaman tersebut. Terjadi pemudaran cahaya dapat juga disebabkan oleh kondisi perairan tidak tenang karena arus atau gelombang. Faktor lain, kemungkinan kepadatan plankton yang cukup tinggi di kolom bagian atas perairan (Nadir, 2000). Kedalaman penetrasi cahaya dalam laut tergantung pada beberapa faktor antara lain absorpsi cahaya oleh partikel-partikel air, panjang gelombang cahaya, kecerahan air, pemantulan cahaya oleh permukaan laut, musim, dan lintasan geografis (Nybaken, 1988).

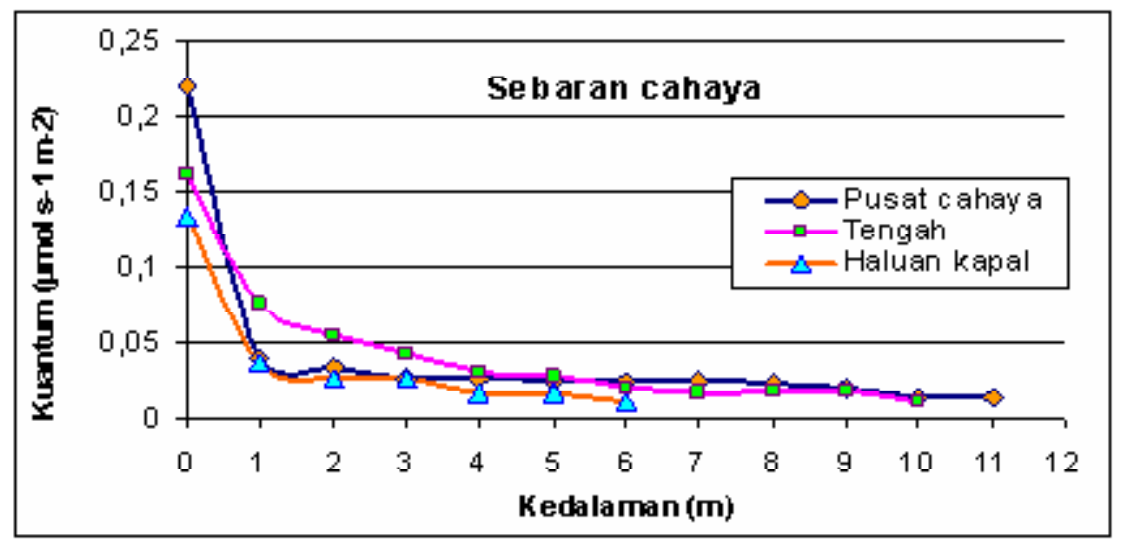

Gambar 2.

Sebaran cahaya vertikal dari permukaan air.

Figure 2.

Vertical light distribution from surface water.

Gambar 3 menunjukkan bahwa sebaran vertikal cahaya mulai dari $1 \mathrm{~m}$ dari permukaan pada lahan pusat cahaya secara efektif (diduga berpengaruh pada mata ikan) terdapat kuat cahaya sampai dengan kedalaman $11 \mathrm{~m}$ dengan nilai kuat cahaya $0,014 \mu \mathrm{mol} \mathrm{s}^{-1} \mathrm{~m}^{-2}$. dan pada jarak $1 \mathrm{~m}$ di bawah permukaan air diperoleh nilai kuat cahaya $0,04 \mu \mathrm{mol} \mathrm{s}^{-1} \mathrm{~m}^{-2}$. Sebaran vertikal cahaya pada lahan tengah cahaya atau kapal secara efektif terdapat kuat cahaya sampai dengan kedalaman $8 \mathrm{~m}$ dengan nilai kuat cahaya $0,08 \mu \mathrm{mol} \mathrm{s} \mathrm{s}^{-1} \mathrm{~m}^{-2}$. Sementara itu, sebaran vertikal cahaya di lahan haluan secara efektif (diduga berpengaruh pada mata ikan) terdapat kuat cahaya sampai dengan kedalaman $6 \mathrm{~m}$ dengan nilai kuat cahaya $0,01 \mu \mathrm{mol} \mathrm{s} \mathrm{s}^{-1} \mathrm{~m}^{-2}$ dan pada jarak $1 \mathrm{~m}$ di bawah permukaan air diperoleh nilai kuat cahaya $0,04 \mu \mathrm{mol} \mathrm{s}^{-1}$ $\mathrm{m}^{-2}$. Gunarso (1985) mengatakan bahwa secara umum ikan dapat memberikan respons terhadap iluminasi cahaya yang lebih rendah yaitu pada kisaran 0,01 sampai dengan 0,001 lux, tergantung kemampuan jenis ikan untuk beradaptasi. Dikatakan oleh Blaxter \& Parish (1958) bahwa cahaya diterima atau direspon oleh ikan melalui mata dan bagian penealyang terletak di bagian atas dekat otak. Menurut Bull (1952) sebagian besar ikan dapat membedakan warna cahaya, sebagian ikan fototaksis positif, dan sebagian lain fototaksis negatif. 


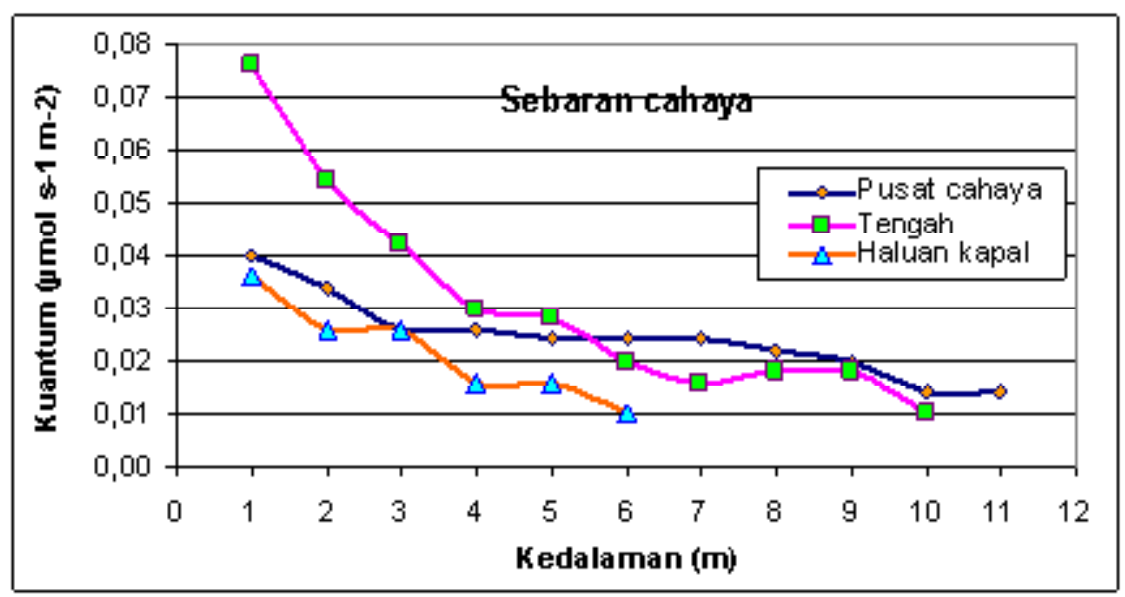

Gambar 3. Sebaran cahaya vertikal mulai $1 \mathrm{~m}$ dari permukaan.

Figure3. Vertical light distribution from $1 \mathrm{~m}$ of surface water.

Hasil analisis regresi menunjukkan hubungan yang berpola eksponensial antara sebaran intensitas cahaya dan kedalaman perairan (Gambar 4). Pola penurunan intensitas cahaya secara eksponensial pada setiap titik lahan pengukuran yaitu $Y=0,0408 \mathrm{e}^{-0,1028 \times}$ (pusat cahaya), $Y=0,0927 e^{-0,2566 x}$ (tengah), dan $Y=0,0459 e^{-0,2385 x}$ (ujung kapal). Dari ke-3 titik pengukuran diperoleh variasi nilai pemudaran cahaya 0,1028 sampai dengan $0,2566 \mu \mathrm{mol}$ $\mathrm{s}^{-1} \mathrm{~m}^{-2}$ per $\mathrm{m}$.

\section{Alat Tangkap dan Armada Penangkapan}

Jaring cumi merupakan salah satu alat tangkap yang relatif baru berkembang di Indonesia, mulai berkembang tahun 2000 di perairan utara Jawa. Banyak armada pukat cincin (purse seine), jaring insang (gill net) dan pukat ikan (fish net), serta cantrang (danish seine) yang beralih fungsi menjadi armada perikanan jaring cumi dan diduga hal ini didorong oleh pertimbangan nilai ekonomi maupun efektivitas perikanan jaring cumi terutama dalam memperoleh hasil tangkapan dan kebutuhan akan bahan bakar yang relatif lebih efisien. Paling tidak saat ini, unit penangkapan jaring cumi menjadi salah satu alternatif bagi usaha perikanan tangkap terutama pada saat mahal harga bahan bakar minyak. Dalam operasi penangkapan unit penangkapan jaring cumi tidak mengoperasikan jaring cumi, tetapi dilengkapi juga dengan alat tangkap lain seperti jaring insang (gill net) dan pancing tangan (hand line) sehingga dalam perolehan hasil tangkapan selain cumi-cumi, juga ikan-ikan yang nilai ekonomis relatif tinggi seperti tenggiri (Scomberomorus sp.), tongkol (Euthynus afinis), dan manyung (Arius sp.).

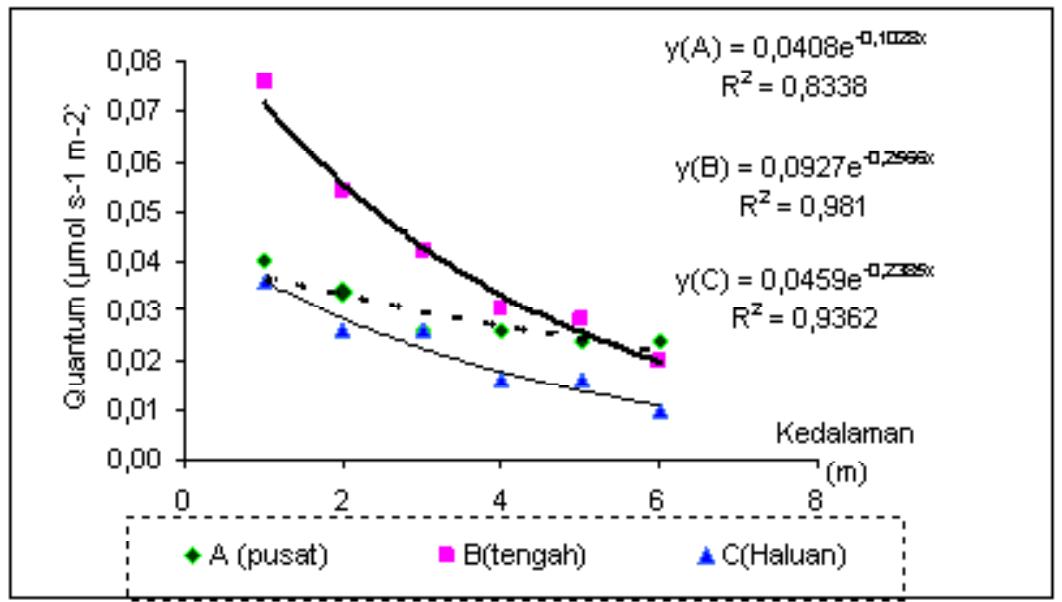

Gambar 4. Hubungan sebaran vertikal intensitas cahaya dengan kedalaman perairan. Figure 4. Relationship between vertical light intensity distribution and waters depth. 
Alat tangkap jaring cumi secara umum, menyerupai alat tangkap jala tebar dan spesifikasi umum jaring cumi tersebut adalah sebagai berikut panjang jaring dari pangkal sampai dengan kantong $12 \mathrm{~m}$, bahan jaring terbuat dari bahan PE dan PA multifilament (d/6 sampai dengan d/15) (Gambar 5). Lebar mata jaring (mesh size) terdiri atas $3 / 4$ inci pada kantong dan 1 inci selain bagian kantong, pada bagian bawah (pangkal) jaring dilengkapi dengan pemberat rantai timah sekitar $150 \mathrm{~kg}$ dan ring 80 buah ( $25 \mathrm{~kg})$. Ring berfungsi juga sebagai kolongan (cincin) tali kolor PE Ø $18 \mathrm{~mm}$ sepanjang $40 \mathrm{~m}$, pada pangkal jaring diberi tali ris $P E \varnothing 8 \mathrm{~mm}$, panjang $32 \mathrm{~m}$.

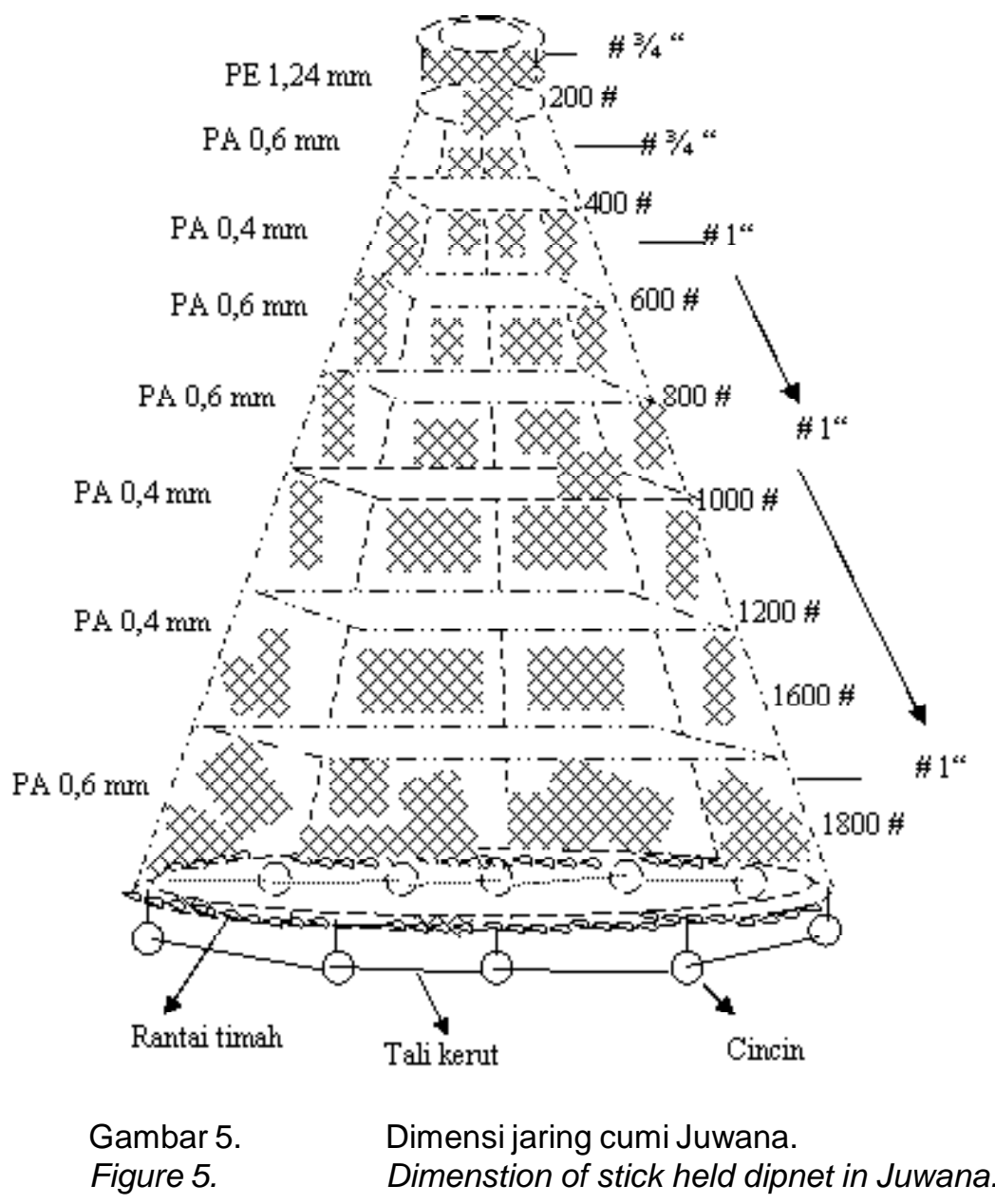

Ukuran kapal jaring cumi yang saat ini, berkembang sangat bervariasi. Armada jaring cumi yang berbasis di Juwana pada umumnya berukuran <30 GT (Gambar 6).

Kapal jaring cumi pada umumnya menggunakan mesin penggerak dengan kekuatan mulai 120 PK (4 sampai dengan 8 silinder) ditambah mesin bantu diesel 20 PK. Daya lampu yang digunakan berkisar mulai dari
10.000 sampai dengan 50.000 watt. Sumber tenaga lampu menggunakan dinamo yang mampu mensuplai daya mulai dari 25.000 sampai dengan 80.000 watt. Pada salah satu sisi kapal dilengkapi 2 buah boom (dari bambu, besi) yang berfungsi untuk merentangkan jaring keluar kapal saat dioperasikan, masing-masing boom panjang $\pm 10 \mathrm{~m}$. Pada boom dilengkapi tali dan pen dari besi untuk mengikat (mengantung) jaring saat dioperasikan. 


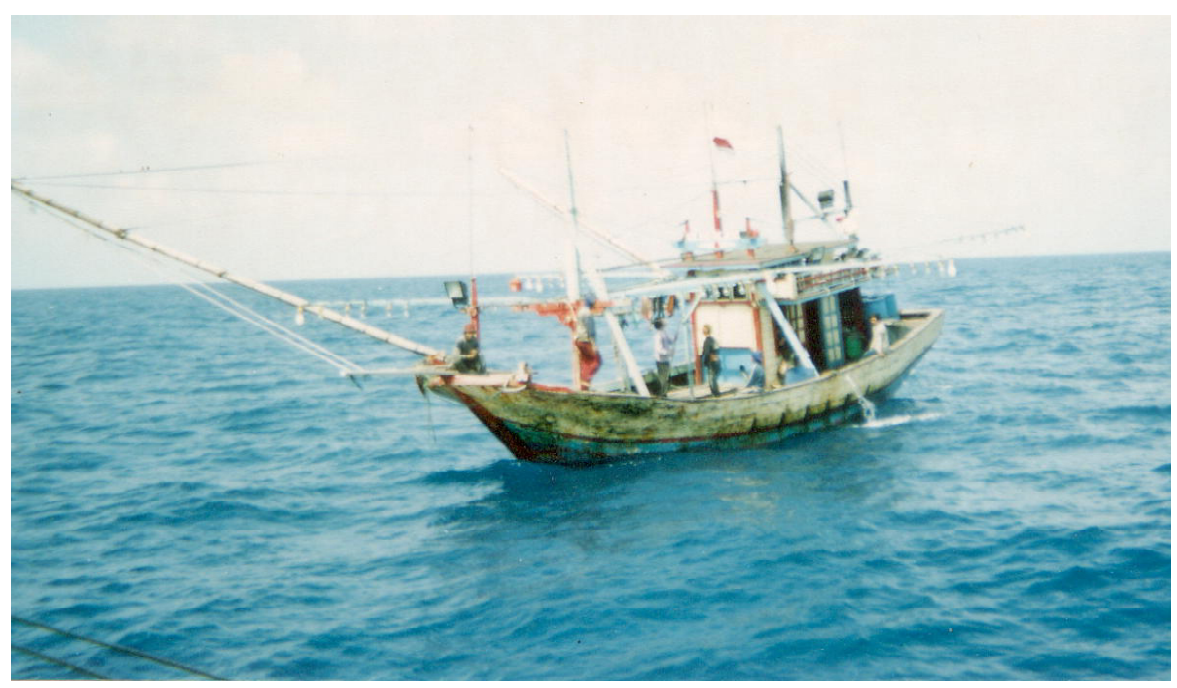

Gambar 6.

Unit penangkapan jaring cumi Juwana.

Figure 6.

Stick held dipnet unit in Juwana.

Berdasarkan pada hasil pengukuran (LOA) pada 15 kapal jaring cumi yang berbasis di Juwana diperoleh kisaran panjang 14,30 sampai dengan 19,10 m; Lebar 4,35 sampai dengan 6,60 m; dalam 2,0 sampai dengan 2,5 m. Selengkapnya, dimensi utama kapal jaring cumi Juwana disajikan pada Tabel 1.

\section{Aktivitas Penangkapan}

Cara pengoperasian jaring cumi adalah dengan mengurung ikan-ikan pelagis yang bergerombol di bawah cahaya lampu dan menutupi bagian bawah jaring dengan cara menarik tali kerut, sehingga ikan ikan yang terkurung jaring di dalam tidak dapat meloloskan diri. Sebagai alat penangkap ikan pelagis, jaring cumi sangat efektif karena dapat mencegah lolos ikan-ikan lewat di antara ke-2 belah sisi bawah dapat teratasi.

Perikanan jaring cumi dalam operasi penangkapan, tidak hanya mengoperasikan jaring cumi tetapi mengoperasikan juga jaring insang (gill net) dan pancing tangan (hand line). Jaring cumi beroperasi dalam 1 trip pada umumnya selama 15 sampai dengan 20 hari (saat gelap bulan). Jumlah anak buah kapal dalam 1 unit penangkapan jaring cumi 7 sampai dengan 9 orang. Cumi sebagai sasaran tangkapan, banyak ditangkap oleh jaring

Tabel 1. Dimensi kapal jaring cumi di Juwana

Table1. Dimention of stick held dipnet boats in Juwana

\begin{tabular}{cccc}
\hline No. & $\begin{array}{c}\text { Panjang } \\
(\mathbf{m})\end{array}$ & $\begin{array}{c}\text { Lebar } \\
(\mathbf{m})\end{array}$ & $\begin{array}{c}\text { Dalam } \\
(\mathbf{m})\end{array}$ \\
\hline 1 & 14,30 & 4,75 & 2,5 \\
2 & 14,35 & 4,35 & 2,3 \\
3 & 16,20 & 4,30 & 2,2 \\
4 & 15,25 & 4,55 & 2,3 \\
5 & 16,50 & 4,50 & 2 \\
6 & 16,15 & 5,20 & 2 \\
7 & 19,10 & 5,55 & 2,5 \\
8 & 15,95 & 4,65 & 2,3 \\
9 & 15,70 & 4,15 & 2 \\
10 & 19,00 & 6,60 & 2,3 \\
11 & 18,60 & 5,65 & 2,3 \\
12 & 15,60 & 4,85 & 2,4 \\
13 & 16,60 & 5,50 & 2,4 \\
14 & 14,50 & 4,80 & 2,4 \\
15 & 15,20 & 4,60 & 2,3 \\
\hline
\end{tabular}


cumi saat musim cumi (bulan Nopember sampai dengan Mei), sedangkan di saat tidak musim cumi kapal jaring cumi beroperasi lebih ditujukan untuk menangkap ikan tenggiri dengan menggunakan pancing tangan (hand line) dan jaring insang, jaring cumi dioperasikan untuk menangkap ikan umpan. Jumlah tawur (setting) jaring cumi dalam 1 malam dapat dilakukan berulang-ulang 6 sampai dengan 8 kali tawur, tergantung ada cumi atau ikan yang berkumpul di bawah cahaya lampu. Cara pengoperasian jaring cumi adalah sebagai berikut:

1. Di daerah penangkapan, kapal jaring cumi mulai meyalakan lampu sekitar pukul 18.00.

2. Setelah ikan banyak berkumpul di bawah cahaya lampu, jaring cumi siap untuk dioperasikan, dengan cara jaring dibentangkan sehingga membentuk segi empat sama sisi, ke-2 kanan dan kiri jaring dikaitkan pada tali yang ada di boom, lalu dijepit dengan sebuah pen (besi) agar mudah lepas saat jaring di jatuhkan.

3. Posisi jaring dalam keadaan rentang, 1 sisi jaring ada di pinggir kapal, dan 3 sisi ada di luar atau di atas permukaan air.

4. Agar ikan lebih terkonsentrasi, lampu secara bertahap dipadamkan sampai dengan hanya 1 lampu (lampu tawur) yang menyala dan telah diberi kap (tutup) berwarna merah (Halogen 400 watt).

5. Setelah diperkirakan ikan terkonsentrasi di bawah sinar lampu (halogen 400 watt), jaring dijatuhkan (dilepas) secara serentak, dengan cara menarik tali pen agar jaring terlepas dari tali boom.

6. Tali pengerut jaring kemudian ditarik dengan bantuan gardan, sampai dengan bagian pangkal jaring mengerut (menutup) sehingga ikan dapat terkurung didalam jaring.

7. Lampu dinyalakan kembali, selanjutnya jaring diangkat ke atas kapal dan ikan yang tertangkap di ambil melalui ujung jaring (kantong).

8. Pengoperasian jaring cumi dilakukan sepanjang malam sampai dengan pukul 05.00.

Nelayan jaring cumi Juwana beroperasi di perairan utara Jawa pada posisi sekitar $03-04^{\circ}$ LS dan $110-114^{\circ}$ BT (Gambar 7). Pada saat musim cumi beroperasi di sekitar utara Pulau Bawean yaitu pada posisi 03-04 LS dan $110-111^{\circ} \mathrm{BT}$ dan saat tidak musim cumi beroperasi pada posisi $03-04^{\circ} \mathrm{LS}$ dan $111-114^{\circ}$ BT untuk menangkapan tenggiri dengan pancing.

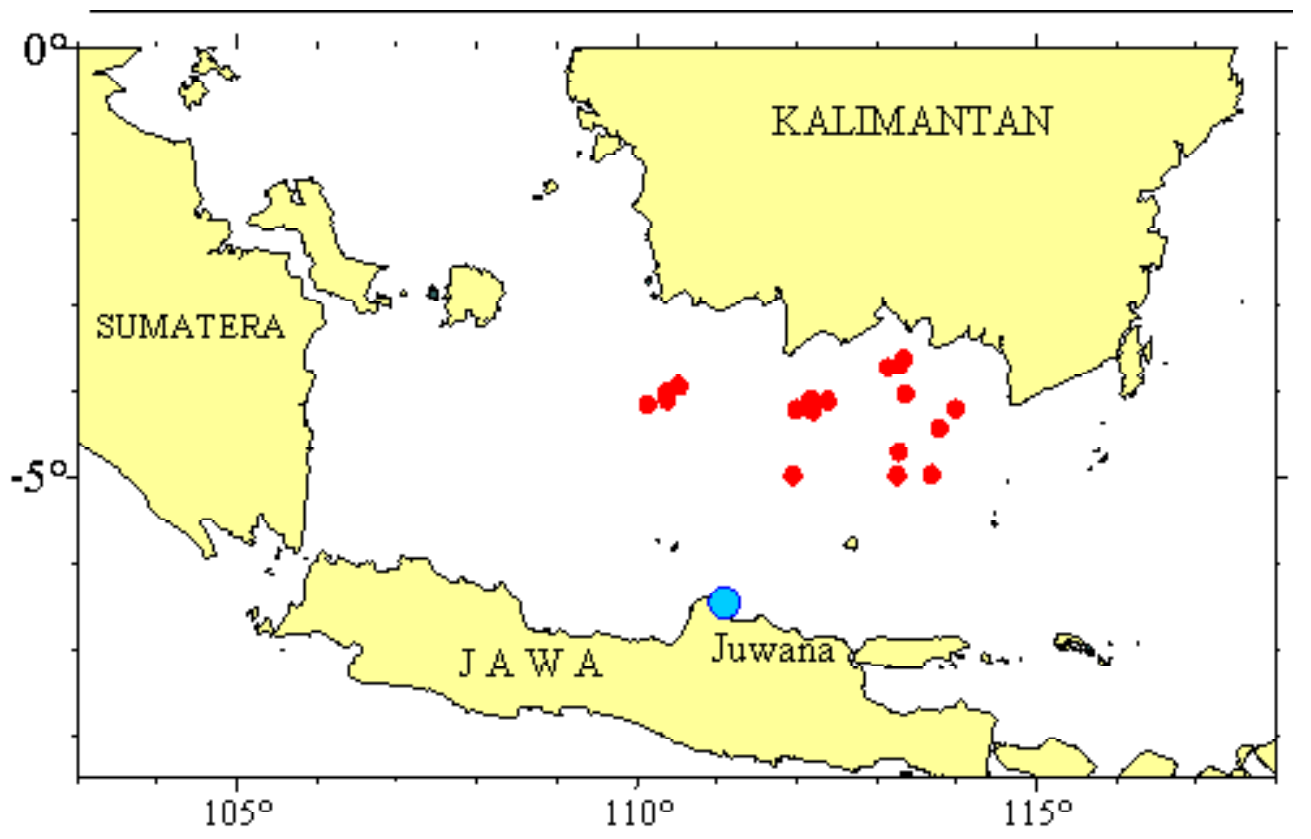

Fishing ground jaring cumi

Gambar 7.

Fishing ground jaring cumi Juwana.

Figure 7.

Fishing ground of stick held dipnet in Juwana. 


\section{Komposisi Hasil Tangkapan}

Berdasarkan pada data yang tersedia (Tabel 2) diperoleh produsi jaring cumi tertinggi ditemukan pada bulan Nopember $82,398 \mathrm{~kg}$ dengan jumlah upaya 33 unit dan produksi terendah terjadi pada bulan Juni $31.320 \mathrm{~kg}$ dengan jumlah upaya 28 unit (Gambar 8 ). Pada Gambar 8 tersebut menunjukkan catch per unit of effort selama bulan April sampai dengan Desember 2005 mengalami fluktusi. Catch per unit of effort relatif tinggi terjadi pada bulan April (1.864 kg per trip) kemudian bulan berikutnya mengalami penurunan sampai dengan bulan Agustus dan secara keseluruhan catch per unit of effort tertinggi terjadi pada bulan Nopember (2.289 kg per trip). Nilai catch per unit of effort tersebut kemungkinan dipengaruhi oleh fluktuasi biomassa atau perkembangan upaya yang sangat cepat, sementara itu laju pertumbuhan stok relatif tetap.

Tabel2. Produksi unit penangkapan jaring cumi di Juwana selama bulan April sampai dengan Desember 2005

Table 2. $\quad$ Production of stick held dipnet boat in Juwana during period April to December 2005

\begin{tabular}{lccccccc}
\hline \multirow{2}{*}{ No. } & \multicolumn{7}{c}{ Bulan/Mounth } \\
\cline { 2 - 7 } & April & Mei & Juni & Juli & Agustus & Nopember & Desember \\
\hline $\begin{array}{l}\text { Produksi (kg) } \\
\text { Jumlah kapal }\end{array}$ & 91.329 & 37.361 & 31.320 & 35.069 & 41.994 & 82.398 & 60.697 \\
$\begin{array}{l}\text { (unit) } \\
\begin{array}{l}\text { CPUE } \\
\text { (kg per unit) }\end{array}\end{array}$ & 1.864 & 29 & 28 & 28 & 33 & 36 & 33 \\
\hline
\end{tabular}

Keterangan/Remarks: Tidak diperoleh data bulan September dan Oktober

Sumber/Sources: TPI Bojomulyo Juwana, Pati

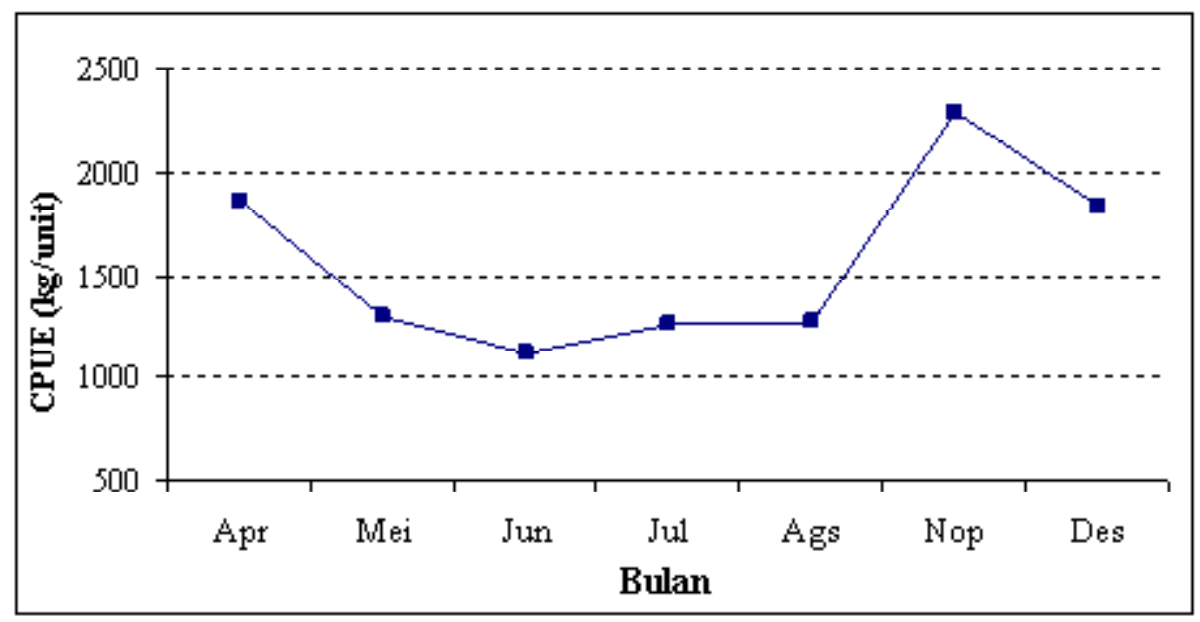

Gambar 8. Fluktuasi catch per unit of effort jaring cumi Juwana (bulan April sampai dengan Desember 2005). Figure 8. $\quad$ Catch rate fluctuation of stick held dipnet in Juwana (April to December 2005).

Dari perolehan tangkapan jaring cumi Juwana selama 1 trip pada bulan Oktober 2004 yang beroperasi pada posisi sekitar $06^{\circ} 44^{\prime} 005^{\prime \prime}$ LS dan $109^{\circ} 19^{\prime} 285^{\prime \prime}$ BT terlihat hasil tangkapan jaring cumi didomininasi oleh ikan siro (Ambygaster sirm) sekitar (83,58\%) dan cumi hanya $4,55 \%$ (Lampiran 1). Rata-rata panjang mantel cumi tarusan (Loligo duvaucelli) 9,67 cm dan rata-rata ukuran FL ikan siro $17,44 \mathrm{~cm}$. Cumi yang tertangkap mempunyai sebaran ukuran panjang mantel berkisar $4,0 \mathrm{~cm}$ sampai dengan $17,9 \mathrm{~cm}$ dengan modus 10,0 sampai dengan 11,9 $\mathrm{cm}$ dan $50 \%$ dari yang tertangkap berukuran $8,0 \mathrm{~cm}$ (Lampiran 2 dan 3). Panjang cagak (FL) ikan siro yang tertangkap jaring cumi didominasi oleh ukuran 17,0 sampai dengan $17,9 \mathrm{~cm}$ FL dan $50 \%$ dari yang tertangkap berukuran $17,5 \mathrm{~cm}$. (Lampiran 4 dan 5). 


\section{KESIMPULAN}

1. Intensitas cahaya secara vertikal pada lahan pusat cahaya mencapai kedalaman $11 \mathrm{~m}$, pada lahan tengah cahaya atau kapal sampai dengan kedalaman 8 dan pada lahan haluan sampai dengan kedalaman $6 \mathrm{~m}$. Dari ke-3 titik pengukuran (pusat, tengah, dan haluan kapal) diperoleh variasi nilai pemudaran cahaya 0,1028 sampai dengan 0,2566 $\mu$ mol s-1 m-2 per m. Dimensi jaring cumi secara umum, panjang jaring dari pangkal sampai dengan kantong $12 \mathrm{~m}$, bahan jaring terbuat dari bahan PE dan PA multifilament (d/6 sampai dengan $\mathrm{d} / 15$ ). Lebar mata jaring (mesh size) terdiri atas $3 / 4$ inci pada kantong dan 1 inci selain bagian kantong.

2. Dimensi kapal jaring cumi yang berbasis di Juwana, panjang berkisar 14,30 sampai dengan $19,10 \mathrm{~m}$; Lebar 4,35 sampai dengan 6,60 m; dan dalam 2,0 sampai dengan $2,5 \mathrm{~m}$. Mesin $120 \mathrm{PK}$, kekuatan lampu berkisar 10.000 sampai dengan 50.000 watt.

3. Jaring cumi dioperasikan dengan cara mengurung ikan-ikan pelagis yang bergerombol di bawah cahaya lampu dan menutupi bagian bawah jaring dengan cara menarik tali kerut, sehingga ikan-ikan terkurung dan tidak dapat meloloskan diri. Jaring cumi beroperasi dalam 1 trip pada umumnya 15 sampai dengan 20 hari.

4. Nelayan jaring cumi di Laut Jawa banyak memperoleh tangkapan cumi pada bulan Nopember sampai dengan Mei dan pada umumnya beroperasi pada posisi 03$04^{\circ}$ LS dan $110-111^{\circ} \mathrm{BT}$.

5. Hasil tangkapan jaring cumi didominasi ikan siro (Amblygaster sirm) sekitar 83,58\% dengan panjang cagak 17,0 sampai dengan $17,9 \mathrm{~cm}$ dan cumi (Loligo sp.) sekitar $4,55 \%$ dengan panjang mantel berkisar 4,0 sampai dengan $17,9 \mathrm{~cm}$.

\section{PERSANTUNAN}

Kegiatan dari hasil riset selektivitas alat tangkap berbasis cahaya di perairan utara Jawa, T.A 2004 dan 2005, di Anggaran Pendapatan Belanja Negara.

\section{DAFTAR PUSTAKA}

Arimoto, T. 1999. Light fishing. Paper in International Fisheries Training Center. JICA. Tokyo. Pp 15 (Unpublished).

Blaxter, J. H. S. \& Parrish B. B. 1958. The effects of artificial ligths on fish and other marine organisms at sea. Journal Marine Resources. 2. 24 pp.

Bull, H. O. 1952. And evaluation of our knowledge of fish behaviour in relation to hydrography. Rapp. ICES. 131: 8-23.

Nadir M. 2000. Teknologi light fishing di perairan Barru Selat Makassar. Thesis. Program Pascasarjana. Institut Pertanian Bogor. Bogor. 87 hal.

Nybakken, J. W. 1988. Biologi laut. Suatu Pendekatan Ekologi. Alih Bahasa: H. M. Eidman et al., Marine Biology an Ecological Approach. PT. Gramedia. Jakarta. 549 hal.

Ayodhyoa, A. U. 1981. Metode penangkapan ikan. Yayasa Dewi Sri. Bogor. 90 hal.

Gunarso. 1985. Tingkah laku ikan dalam hubungannya dengan metoda dan teknik penangkapan. Institut Pertanian Bogor. Fakultas Perikanan. Bogor. 149 hal.

Nikoronov, I. V. 1975. Interaction of fishing gear with fish aggregations. Keter. Publishing House Jerusalem Ltd. Israel. $216 \mathrm{p}$.

Subani, W. 1983. Penggunaan lampu sebagai alat bantu penangkapan ikan. Laporan Penelitian Perikanan Laut No.27/1983. Balai Penelitian Perikanan Laut. Badan Penelitian dan Pengembangan Pertanian. Departemen Pertanian. Jakarta. Hal.45-68.

Tarp, T. G. \& P. J. Kailola. 1982. Trawled fishes of Southern Indonesia and North-Western Australia. ADAB. GDF and GTZ. Singapore. 406 p.

Wahyono, P. B. 2004. Analisis penangkapan jaring cumi pada kapal motor sumber bahari di PPP Bajomulyo. Skripsi. Program Studi Pemanfaatan Sumber Daya Perikanan. Fakultas Perikanan dan IImu Kelautan. Institut Pertanian Bogor. Bogor. 71 hal. 


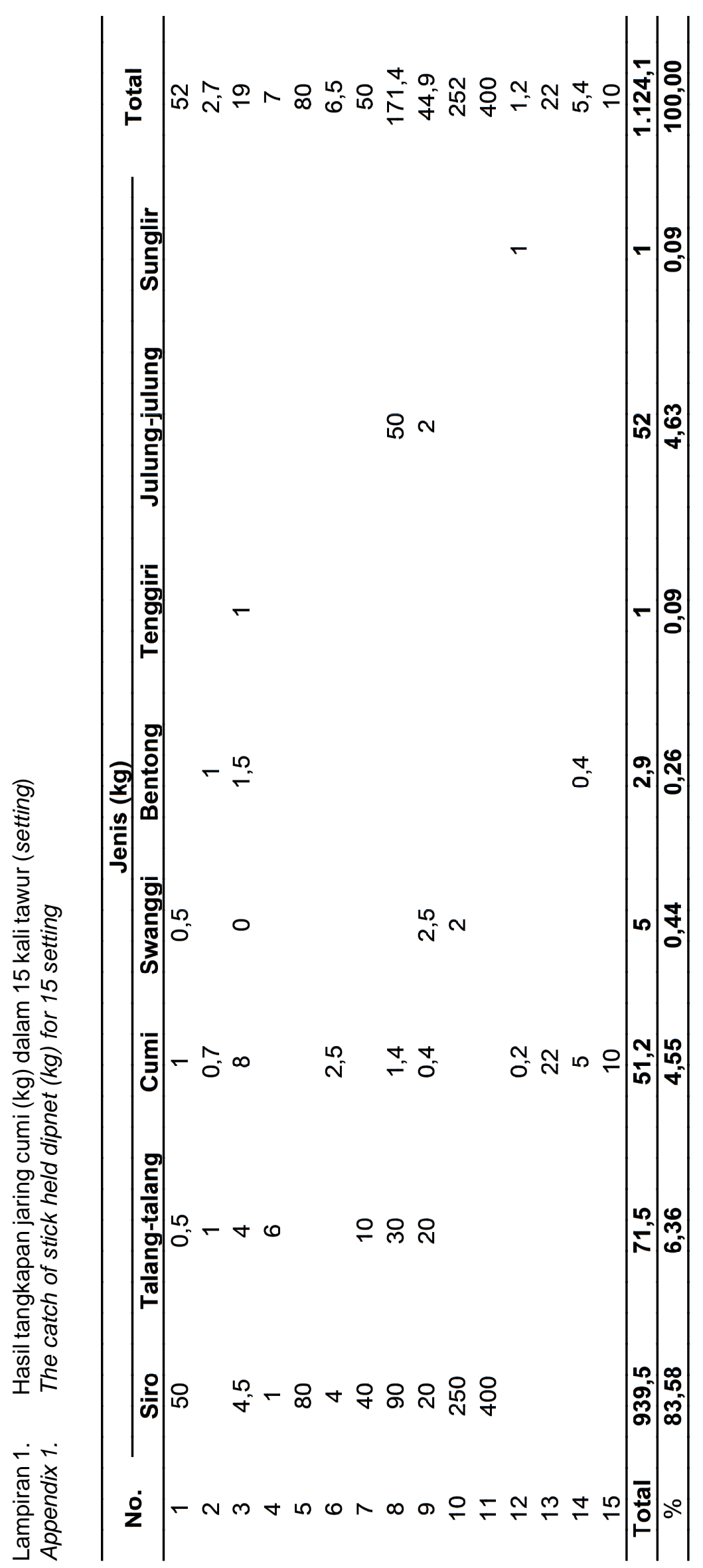


Lampiran 2. Sebaran ukuran panjang mantel cumi-cumi yang tertangkap jaring cumi Appendix 2. Lengt frekwency distribution of squid caught by stick held dipnet

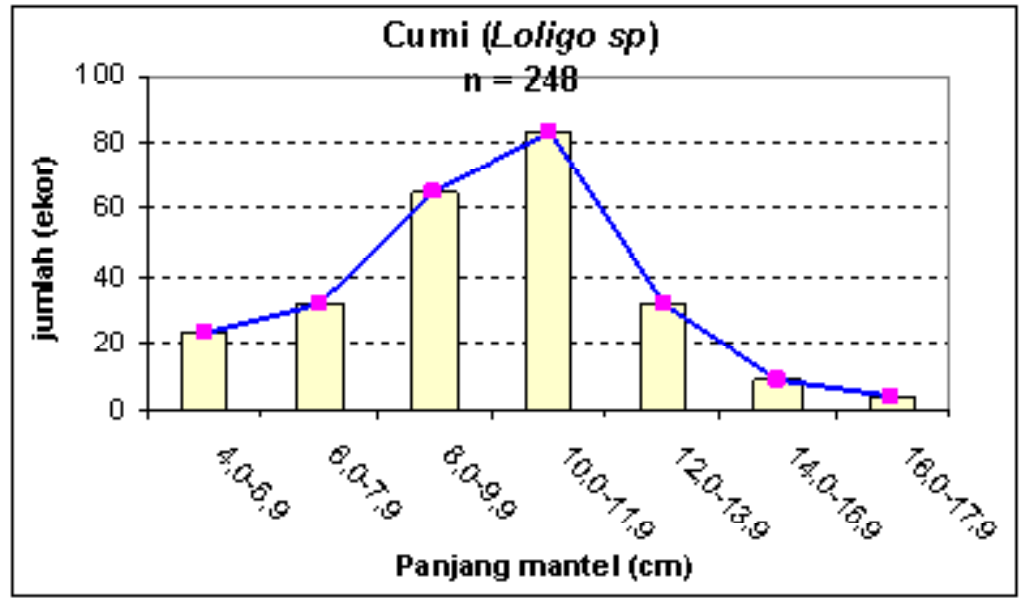

Lampiran 3. Sebaran ukuran panjang mantel cumi-cumi yang tertangkap jaring cumi Appendix 3. Lengt frekwency distribution of squid caught by stick held dipnet

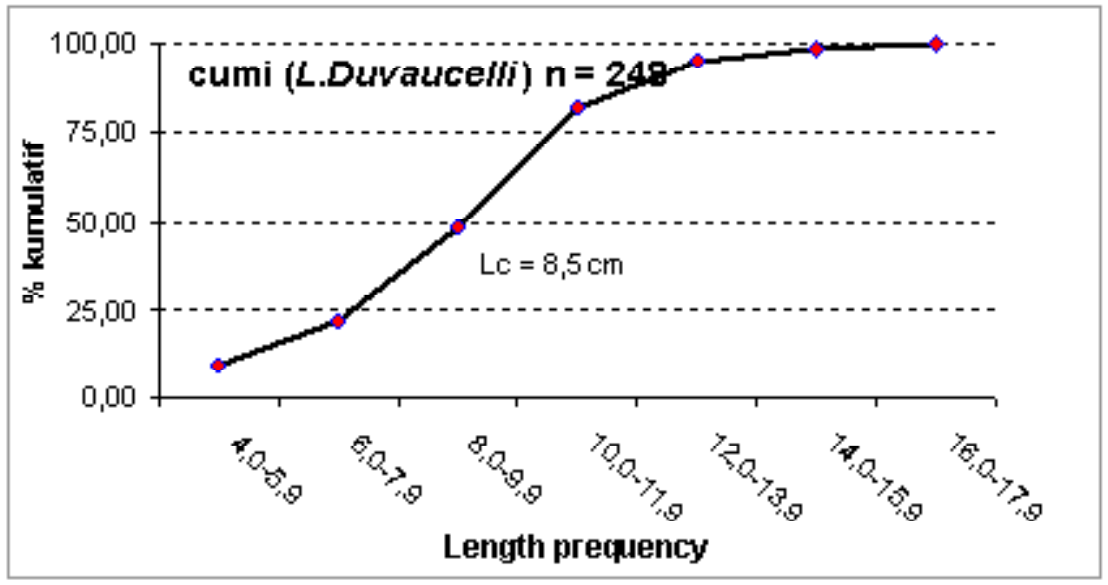


Lampiran 4. Sebaran ukuran panjang mantel ikan siro (Amblygaster sirm) yang tertangkap jaring cumi Appendix 4. Lengt frekwency distribution of siro (Amblygaster sirm) caught by stick held dipnet

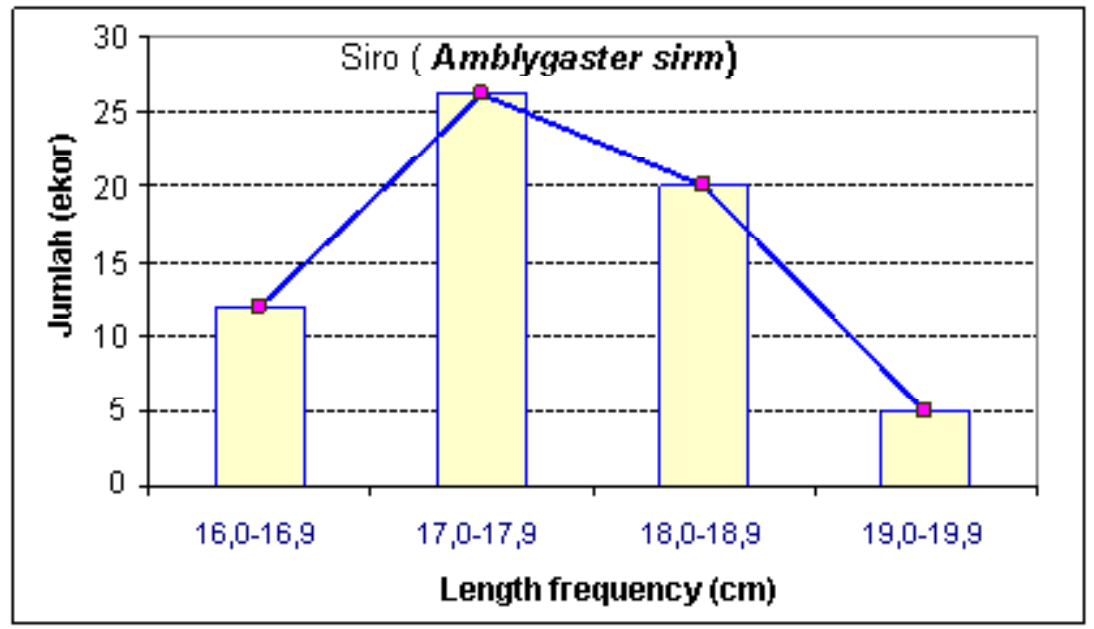

Lampiran 5. ukuran panjang mantel ikan siro (Amblygaster sirm) yang tertangkap jaring cumi Appendix 5. Lengt frekwency of Siro (Amblygaster sirm) that catch of of stick held dipnet

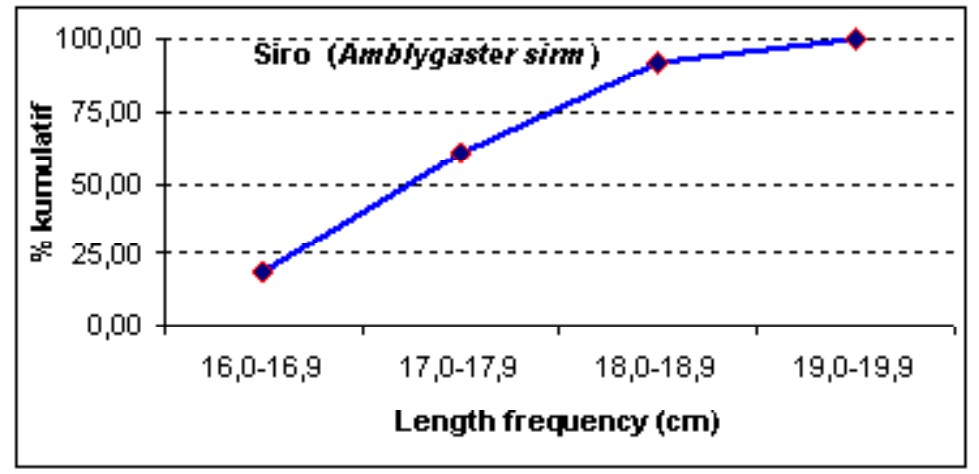

